\title{
RANCANG BANGUN PENJUALAN BRANKAS BERBASIS WEB PADA PT. PERSINDO PERTIWI AGUNG JAKARTA
}

\author{
Agustiena Merdekawati ${ }^{1)}$, Mulyadi Nugroho ${ }^{2)}$ \\ ${ }^{1}$ Manajemen Informatika, AMIK Bina Sarana Informatika \\ email: agustiena.atd@bsi.ac.id \\ ${ }^{2}$ Sistem Informasi, STMIK Nusa Mandiri \\ email: mulyadi_nugroho@yahoo.com
}

\begin{abstract}
Abstrak
PT. Persindo Pertiwi Agung bergerak dibidang penjualan brankas yang sudah mempunyai website, tetapi website tersebut hanya berisi informasi produk yang di pasarkan, untuk sistem penjualannya tidak ada. Sehingga dalam melakukan transaksi penjualannya melalui customer service dan harus bertemu langsung dengan staff marketing sehingga dianggap masih membutuhkan waktu yang cukup lama. Penelitian ini menggunakan metode pengumpulan data yang digunakan penulis yaitu observasi, wawancara, dan studi pustaka untuk mencari permasalahan yang terjadi. Dari permasalahan yang timbul penulis mencoba membuat aplikasi berbasis web menggunakan metode waterfall. Sedangkan sebagai tools-nya penulis membuat ERD, LRS dan UML. Selain untuk sarana informasi yang disajikan secara online juga untuk memudahkan pembeli untuk mengetahui detail brankas, serta melakukan transaksi didalam sistem. Dengan adanya website ini diharapkan dapat membantu pembeli dan staff marketing dalam mempromosikan brankas ke pembeli perorangan, mengolah data transaksi dan menghasilkan informasi yang akurat, cepat dan hemat.
\end{abstract}

Kata kunci: Penjualan, Brankas, Website

\begin{abstract}
PT. Persindo Pertiwi Agung is engaged in the sale of safes that already have a website, but the website only contains product information that is marketed, for the sales system does not exist. So in conducting sales transactions through customer service and must meet directly with the marketing staff so it is considered still takes a long time. This study uses data collection methods used by the author of observation, interviews, and literature study to find the problems that occur. From the problems that arise the author tries to make a web-based application using waterfall method. While as his tools the author makes ERD, LRS and UML. In addition to the means of information presented online as well as to facilitate the buyer to know the details of the safe, as well as perform transactions within the system. With this website is expected to assist buyers and marketing staff in promoting safes to individual buyers, process transaction data and produce information that is accurate, fast and efficient.
\end{abstract}

Keywords: sales, safe, website

\section{PENDAHULUAN}

Persaingan dalam dunia bisnis sekarang ini sangat ketat. Untuk memperlancar serta bertahan, suatu badan usaha harus mempunyai kualitas kerja yang baik dan terstruktur. Ditambah lagi, perkembangan teknologi sekarang ini khususnya teknologi informasi berkembang dengan sangat pesat. Dalam suatu perusahaan, komputer digunakan untuk mendukung aktivitas perusahaan, antara lain produksi, komunikasi, dan teknologi informasi. Banyak sekali kegiatan yang dapat dikerjakan dengan bantuan media komputer dan aplikasi internet. Salah satu keuntungan dan manfaat dari adanya internet yang akan dibahas pada penulisan kali ini adalah e-commerce. E-commerce ini 
dapat digunakan sebagai suatu sarana untuk memperluas pemasaran dan jaringan penjualan perusahaan, sehingga jangkauan pemasaran dan penjualan dapat semakin luas dan tidak terbatas hanya pada satu wilayah/perusahaan tertentu. Serta dapat mempermudah proses transaksi penjualan dan pengolahan laporan penjualan.

PT. Persindo Pertiwi Agung merupakan perusahaan yang bergerak dibidang penjualan brankas dan pengamanan. Proses promosi sudah menggunakan website, namun pemesanan masih melalui pihak customer service atau marketing melalui email dan telepon, pendataan pemesanan atau penjualan masih menggunakan pengarsipan dokumen PO (Purchase Order) dan Microsoft Excel, sampai tahap pembuatan laporan masih menggunakan sistem manual, dengan menggunakan excel. Kendala yang terjadi dengan sistem tersebut adalah kurang praktisnya proses penjualan, sering terjadinya kesalahan dalam pemberian informasi produk, pengarsipan dokumen yang mudah hilang, pengolahan transaksi yang kurang akurat dan juga pembuatan laporan penjualan yang masih menggunakan Excel.

Untuk mengatasi kebutuhan dan pelayanan bisnis dalam proses pemesanan dan penjualan, informasi produk termasuk proses pengolahan data-data yang berkaitan dengan kegiatan promosi, pembayaran pembuatan laporan penjualan diperlukan sebuah sistem informasi yang baik. Sistem informasi ini bukan hanya sekedar untuk menutupi kelemahan manajemen yang sudah berjalan, namun dapat meningkatkan dan menunjang mutu pelayanan dalam pengolahan data-data dan dokumen-dokumen yang berkaitan dalam proses pemesanan dan penjualan.

\section{STUDI LITERATUR Penjualan}

Penjualan adalah bagian dari promosi dan promosi adalah salah satu bagian dari keseluruhan sistem pemasaran (Abdullah dan Tantri, 2016)

Menurut Mcleod dan Schell dalam Ardiansyah dan Herlawati (2015:1),
Perdagangan elektronik yang disebut juga e-commerce adalah penggunaan internet dan komputer dengan browser web untuk membeli dan menjual produk.

Menurut Kurniawan dalam Riyanti dan Baidawi, E-Commerce adalah suatu jenis dari mekanisme bisnis secara elektronik yang memfokuskan diri pada transaksi bisnis berbasis individu dengan menggunakan internet ( teknologi berbasis jaringan digital) sebagai medium petukaran barang atau jasa baik antara dua buah institusi (business to business) dan konsumen langsung (business to consumer), melewati kendala ruang dan waktu yang selama ini merupakan hal-hal yang dominan.

\section{Website}

Menurut Arief dalam Riyanti dan Baidawi, world wide web, lebih dikenal dengan web, merupakan kumpulan situs web yang dapat diakses di internet yang berisikan semua informasi yang dibutuhkan semua pengguna internet.

Menurut Dengen dan Khairina dalam Utami dan Agustina (2014), aplikasi web merupakan salah satu layanan yang didapat oleh pemakai komputer yang terhubung internet dengan fasillitas hypertext dengan menampilkan data berupa text, gambar, suara, animasi dan data multimedia lainnya.

Website sering diangkat dengan istilah situs yang diartikan sebagai "sejumlah halaman web yang memiliki topik saling terkait, disertai dengan berkas-berkas gambar, video, animasi, data yang berbentuk teks, atau jenis-jenis berkas lainnya" menurut Dianing dalam Utami dan Agustina (2014)

\section{Konsep Dasar Pemrograman}

"Adobe Dreamweaver CS6 adalah suatu perangkat lunak web editor keluaran Adobe System yang digunakan untuk membangun dan mendesain suatu website dengan fitur-fitur yang menarik dengan kemudahan dalam penggunaannya" (Sadeli, 2013)

Menurut Sadeli (2013), PHP merupakan bahasa pemrograman yang ditujukan untuk membuat aplikasi yang berbasis web. Ditinjau dari pemrosesannya, 
PHP tergolong sebagai server side, yaitu pemrosesan yang dilakukan di server.

Menurut Madcoms

(2016)

"JavaScript adalah bahasa (pemrograman) yang hebat, meskipun cenderung sulit untuk dipahami, akan tetapi kemampuan inti yang dimiliki oleh JavaScript sangat menarik untuk didalami”. Dengan JavaScipt anda dapat membuat aplikasi-aplikasi hebat seperti Google Maps. Java Script telah merubah pandangan dunia terhadap internet (web).

Menurut Kadir (2013), "MySql adalah database server yang berfungsi untuk menangani database". "MySQL adalah Relational Database Management System (RDBMS) yaitu database relasi yang memiliki perintah dasar SQL". Menurut Madcoms (2016) "MySQL adalah sistem manajemen database SQL yang bersifat Open Source dan paling populer saat ini. Sistem Database MySQLmendukung beberapa fitur seperti multithreaded, multi-user, dan SQL database management system (DBMS). Database ini dibuat untuk keperluan sistem database yang cepat, handal, dan mudah digunakan".

Mulhim (2013), "XAMPP adalah paket instalasi program yang terdiri atas program Apache HTTP Server, MySQL Database, dan penerjemahan bahasa yang ditulis dalam bahasa pemrograman PHP dan Perl". Mirza (2013), "XAMPP adalah paket program berbasis web yang didalamnya berisi software apache, PHP, dan database MySQL". "XAMPP merupakan paket PHP dan MySQL berbasis open source, yang dapat digunakan sebagai tool pembantu pengembangan aplikasi berbasis PHP“. (Riyanto, 2014)

Menurut Sadeli (2013) memberi batasan bahwa "phpMyAdmin adalah sebuah software yang berbentuk seperti halaman situs yang terdapat pada web server. Fungsi dari halaman ini adalah sebagai pengendali database MySQL sehingga pengguna lain $M y S Q L$ tidak perlu repot untuk menggunakan perintah-perintah $S Q L$. Karenanya dengan adanya halaman ini semua hal tersebut dapat dilakukan hanya dengan meng-klik menu fungsi yang ada pada halaman phpMyAdmin.

\section{METODE PENELITIAN}

Menurut Sukamto dan Shalahudin (2013) menyatakan bahwa : SLDC (Software Development Life Cycle) atau sering disebut juga System Development Life Cycle adalah proses mengembangkan atau mengubah suatu sistem perangkat lunak dengan menggunakan model-model dan metodologi yang digunakan orang untuk mengembangkan sistem-sistem perangkat lunak sebelumnya (berdasarkan best practice atau cara-cara yang teruji baik).

Tahapan-tahapan metode penelitian yang ada pada model waterfall, sebagai berikut: (Sukamto dan Shalahudin, 2013)

1. Analisa Kebutuhan Perangkat Lunak Merupakan proses pengumpulan kebutuhan dilakukan secara intensif untuk menspesifikasikan kebutuhan perangkat lunak agar dapat dipahami perangkat lunakseperti apa yang dibutuhkan oleh user. Spesifikasi kebutuhan perangkat lunak pada tahap ini perlu untuk didokumentasikan.

2. Desain.

Desain perangkat lunak adalah proses multi langkah yang fokus pada desain pembuatan program perangkat lunak, termasuk struktur data, arsitektur perangkat lunak, representasi antarmuka, dan prosedur pengkodean. Tahap ini mentranslasikebutuhan perangkat lunak dari tahap analisa kebutuhan kerepresentasi desain agar dapat diimplementasikan menjadi program pada tahap selanjutnya.

3. Pembuatan kode program

Desain harus ditranslasikan ke dalam program perangkat lunak. Hasil dari tahap ini adalah program komputer sesuai dengan desain yang telah dibuat pada tahap desain.

4. Pengujian

Pengujian fokus pada perangkat lunak secara dari segi logik dan fungsional dan memastikan bahwa semua bagian sudah diuji. Hal ini dilakukan untuk meminimalisir kesalahan (error) dan 
memastikan keluaran yang dihasilkan sesuai dengan yang diinginkan.

5. Pendukung (Support) atau Pemeliharaan (maintenance)

Tidak menutup kemungkinan sebuah perangkat lunak mengalami perubahan ketikasudah dikirimkan ke user. Perubahan bisa terjadi karena adanya kesalahan yang muncul dan tidak terdeteksi daat pengujian atau perangkat lunak harus beradaptasi dengan lingkungan baru. Tahap pendukung atau pemeliharaan dapat mengulangi proses pengembangan mulai dari analisis spesifikasi untuk perubahan perangkat lunakyang sudah ada, tapi tidak untuk membuat perangkat lunak baru.

\section{HASIL DAN PEMBAHASAN \\ Sistem Berjalan Penjualan Pada PT. Persindo Pertiwi Agung}

Proses pembelian berawal ketika customer membutuhkan brankas untuk keperluan kantor ataupun pribadi, customer tersebut kemudian menginformasikan perihal kebutuhan brankas melalui E-mail ataupun melalui telphone kepada customer service atau pun marketing untuk mengetahui harga. Ketika sudah mendapatkan harga dan informasi brankas yang di inginkan, untuk Customer perorangan (personal) tidak perlu mengirimkan $\mathrm{PO}$ dan pemesanan dengan

Bentuk dokumen yang ada di dalam usaha penjualan pada PT. Persindo Pertiwi Agung, yang meliputi dokumen masukan dan keluaran, sebagai berikut :

\section{Nama Dokumen : PO (Purchase Order)}

Format : Lampiran A-1

2. Nama Dokumen : Invoice

Fungsi $\begin{aligned} & \text { :Sebagai bukti pembayaran } \\ & \text { pesanan }\end{aligned}$
Sumber : Marketing
Tujuan : Pembeli
Media : Kertas
Jumlah : Dua lembar
Frekuensi:Setiap setelah terjadi
pembayaran transaksi
Format : Lampiran A-2
Nama Dokumen : Faktur Pajak

3. Nama Dokumen : Faktur Pajak menginformasikan produk yang ingin dibeli kepada customer service atau marketing secara langsung. Sedangkan untuk customer (perusahaan) dapat langsung mengirimkan $\mathrm{PO}$ via E-mail kepada marketing. PO yang di terima marketing kemudian langsung diserahkan dan diproses oleh seketaris agar di data dan di keluarkan performa invoice penagihan. Ketika sudah di keluarkan performa invoice kemudian di lanjutkan kebagian staff administrasi untuk pendataan dan mengeluarkan faktur pajak lalu di lanjutkan keproses pengiriman penagihan kepada kurir, sebelum diberikan kepada kurir di emailkan terlebih dahulu oleh seketaris kepada customer. Setelah selesai proses penagihan, customer tersebut melakukan pembayaran brankas sesuai perfoma invoice yang di tagihkan, ketika sudah dilakukan pembayaran. Kemudian bagian staff administrasi menginformasikan pemesanan tersebut dengan memberikan surat jalan kepada kepala gudang dan kepala pengiriman untuk pejadwalan pengiriman brankas. Ketika selesai proses pengiriman brankas proses selanjutnya yaitu penyetingan kunci kombinasi. Jika customer menginginkan untuk perubahan kunci kombinasi, bagian staff administrasi akan membuat surat jalan penyettingan kombinasi, kemudian akan diserahkan kepada bagian teknisi untuk dilakukan penyetingan kunci kombinasi. Fungsi : Sebagai dokumen pemesanan

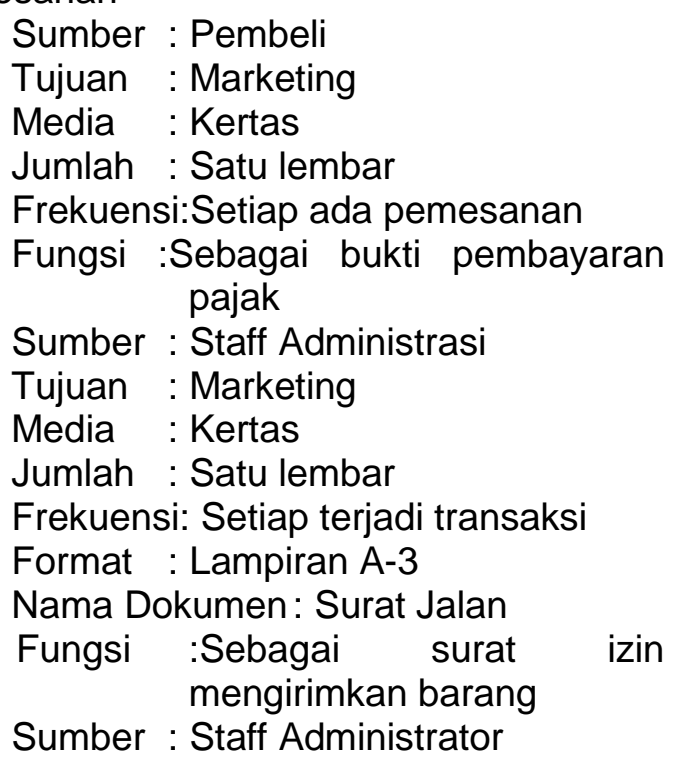




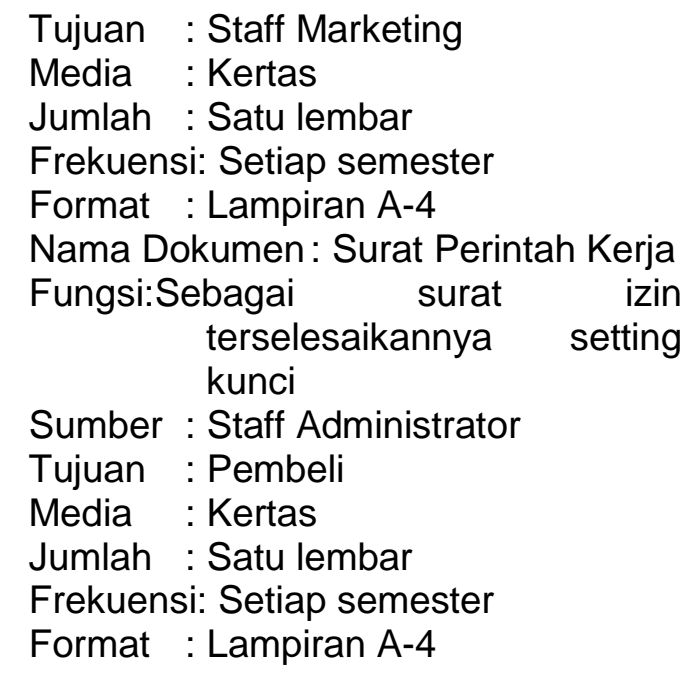

\section{Sistem Yang Diusulkan Pada PT. Persindo Pertiwi Agung}

Rancang bangun penjualan pada PT. Persindo Pertiwi Agung berbasis web ini dimana pembeli tidak harus bertemu langsung dengan marketing, Pembeli dapat melakukan pembelian melalui media browser dan internet lalu mengakses website www.brankaspersindo.com.

Adapun tahap metode penelitian dalam pelitian ini menggunakan metode waterfall, sebagai berikut :

1. Analisa Kebutuhan Perangkat Lunak

Pada tahap ini dokumen yang dibutuhkan yaitu dokumen masukan, berupa nota pemesanan barang, faktur pengiriman barang, serta dokumen keluaran kwitansi pembayaran dan laporan transaksi. Interface yang dibutuhkan menu login admin, halaman input hubungi kami, halaman lihat hubungi kami, halaman laporan, halaman produk, halaman detail poduk, halaman tentang kami, halaman konfirmasi pembayaran, halaman kontak kami, halaman status order, halaman keranjang belanja.

2. Desain.

Pada tahap ini, penulis akan menggambarkan database menggunakan ERD (Entity Relationship Diagram), sedangkan desain sistem menggunakan UML (Unified Modelling Language) menggunakan activity diagram, usecase diagram, deployment diagram, dan component diagram.

3. Pembuatan kode program

Pada tahap ini akan menghasilkan program komputer sesuai dengan desain yang telah dibuat pada tahap desain. Dan bahasa pemrograman yang digunakan ialah PHP (Hypertext Preprocessor), dengan teknik pemrograman yang diambil adalah pemrograman terstruktur. PHP adalah bahasa script yang dapat ditanamkan atau disipkan kedalam HTML. Dan untuk pembuatan databasenya mengunakan MySQL.

4. Pengujian

Teknik pengujian yang dipilih adalah black-box testing, dalam pengujian dilakukan pada halaman alamat pengiriman, halaman konfirmasi pembayaran, halaman hubungi kami, halaman login admin, halaman input produk.

5. Pendukung (Support) atau Pemeliharaan (maintenance)

Hardware yang digunakan perlu memiliki spesifikasi yang meliputi monitor, CPU (Central Processing Unit), mouse, modem (modulator demodulator), dan keyboard. Software yang diperlukan yaitu sistem operasi seperti Windows XP, Windows 7 dan browser seperti Google Chrome atau Mozilla Firefox, Internet Explorer, agar aplikasi dapat digunakan lebih baik oleh user.

Tidak menutup kemungkinan sebuah perangkat lunak mengalami perubahan ketikasudah dikirimkan ke user. Perubahan bisa terjadi karena adanya kesalahan yang muncul dan tidak terdeteksi daat pengujian atau perangkat lunak harus beradaptasi dengan lingkungan baru. Tahap pendukung atau pemeliharaan dapat mengulangi proses pengembangan mulai dari analisis spesifikasi untuk perubahan perangkat lunakyang sudah ada, tapi tidak untuk membuat perangkat lunak baru.

Berikut adalah spesifikasi dari penjualan brankas berbasis web pada PT. Persindo Pertiwi Agung yang diusulkan.

Analisa kebutuhan halaman pembeli : 
A.1. Pembeli dapat melihat atau memilih produk pada halaman beranda.

A.2. Pembeli dapat melihat tentang perusahaan, yang berisi Pemilihan company profile, Kenapa memilih merk cassa, dan informasi brankas cassa.

A.3. Pembeli dapat melihat cara pemesanan.

A.4. Pembeli dapat mengisi Hubungi kami, apabila ada pertanyaan mengenai pemesanan.

A.5. Pembeli dapat melihat kontak kami, yang berisi alamat dan nomer telphone perusahaan apabila ada pertanyaan mengenai pemesanan.

A.6.Pembeli dapat memilih barang berdasarkan kategori.

A.7. Pembeli dapat melakukan pembelian.

A.8. Pembeli dapat melakukan konfirmasi pembayaran.

A.9. Pembeli dapat melakukan pencarian produk atau artikel.

A.10.Pembeli dapat melihat status transaksi pada pencarian status transaksi.

Analisa Kebutuhan halaman Administrator:

B.1.Administrator dapat mengelola data kategori.

B.2.Administrator dapat mengelola data produk.

B.3. Administrator dapat mengelola data order.

B.4. Administrator dapat mengelola data admin.

B.5. Administrator dapat mengelola artikel company overview.
B.6. Administrator dapat mengelola artikel kenapa cassa???.

B. 7.Administrator dapat mengelola artikel brankas cassa.

B.8.Administrator dapat mngelola data hubungi kami.

B.9. Administrator dapat mengelola data kontak kami.

B.10.Administrator dapat mengelola data cara pemesanan.

B.11.Administrator dapat mengelola data konfirmasi pembayaran.

B.12.Administrator dapat melihat data laporan berdasarkan tanggal.

\section{Analisa Kebutuhan Halaman Pembeli}

Pembeli dapat melihat atau memilih produk pada halaman beranda, melihat tentang perusahaan, yang berisi Pemilihan company profile, Kenapa memilih merk cassa, dan informasi brankas cassa, dapat melihat cara pemesanan, dapat mengisi Hubungi kami, apabila ada pertanyaan mengenai pemesanan, dapat melihat kontak kami, yang berisi alamat dan nomer telphone perusahaan apabila ada pertanyaan mengenai pemesanan, dapat memilih barang berdasarkan kategori, dapat melakukan pembelian, dapat melakukan konfirmasi pembayaran, dapat melakukan pencarian produk atau artikel, dan dapat melihat status transaksi pada pencarian status transaksi. Berikut usecase diagram halaman pembeli seperti dibawah ini :

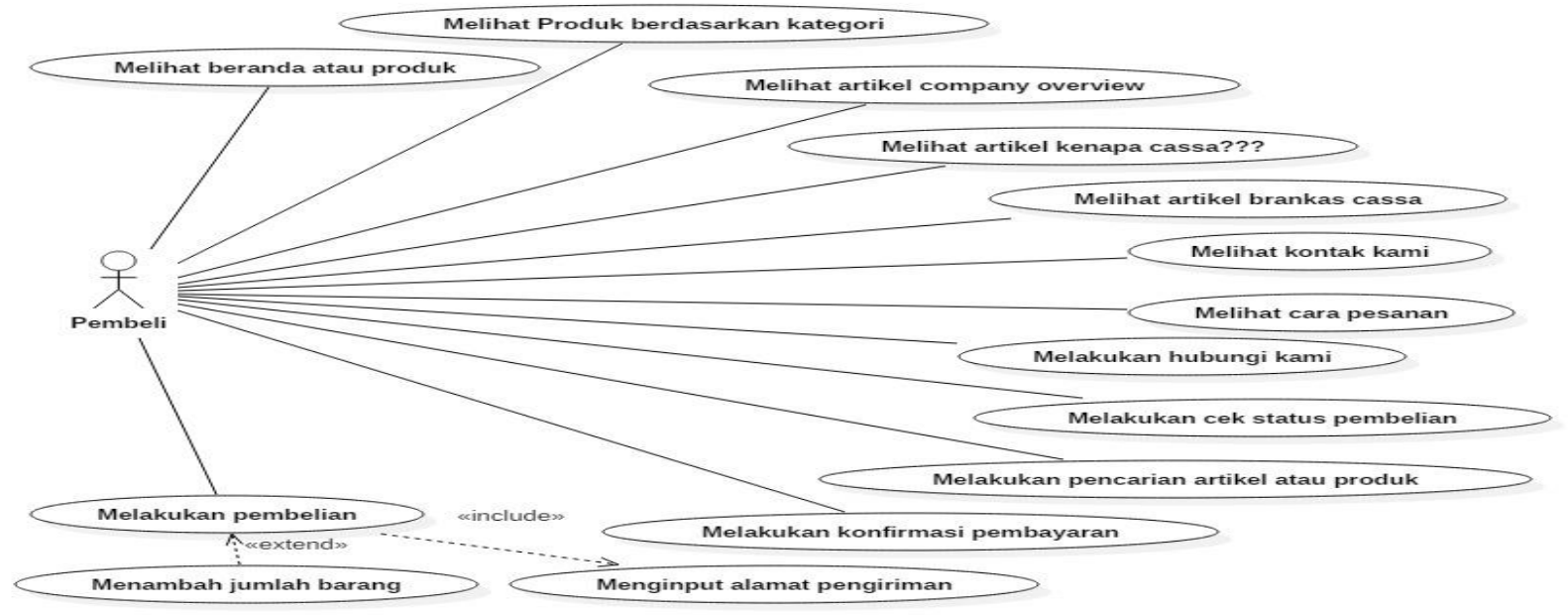

Gambar 1. Usecase Diagram Halaman Pembeli 
Activity diagram halaman pembeli sebeagai berikut :

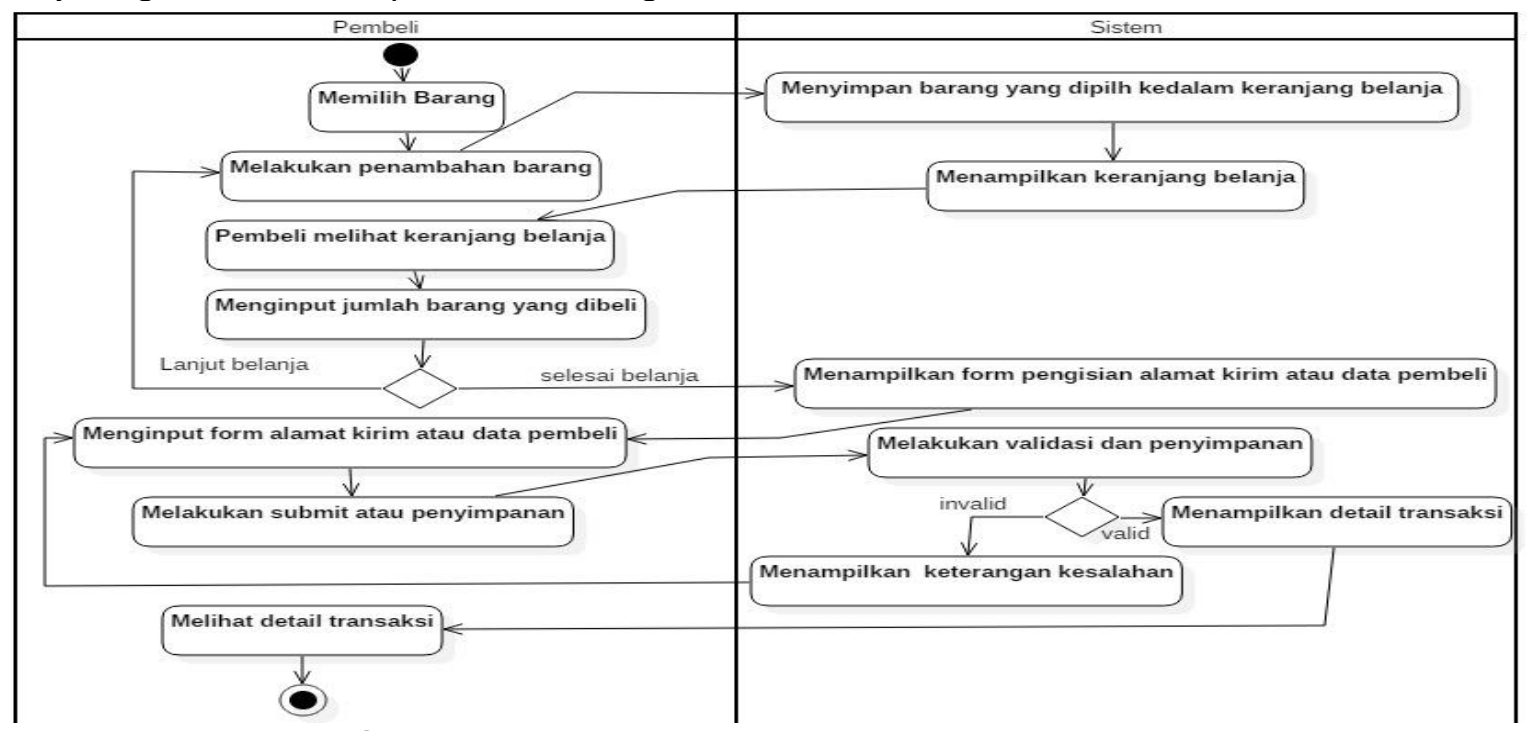

Gambar 2. Activity Diagram Halaman Pembelian

Analisa Kebutuhan Halaman

Administrator

Administrator dapat mengelola data kategori, mengelola data produk, mengelola data order, mengelola data admin, mengelola artikel company overview, mengelola artikel kenapa cassa???, mengelola artikel brankas cassa, mengelola data hubungi kami, mengelola data kontak kami, mengelola data cara pemesanan, mengelola data konfirmasi pembayaran, dan dapat melihat data laporan berdasarkan tanggal.

Penggambaran usecase diagram halaman admin sebagai berikut:

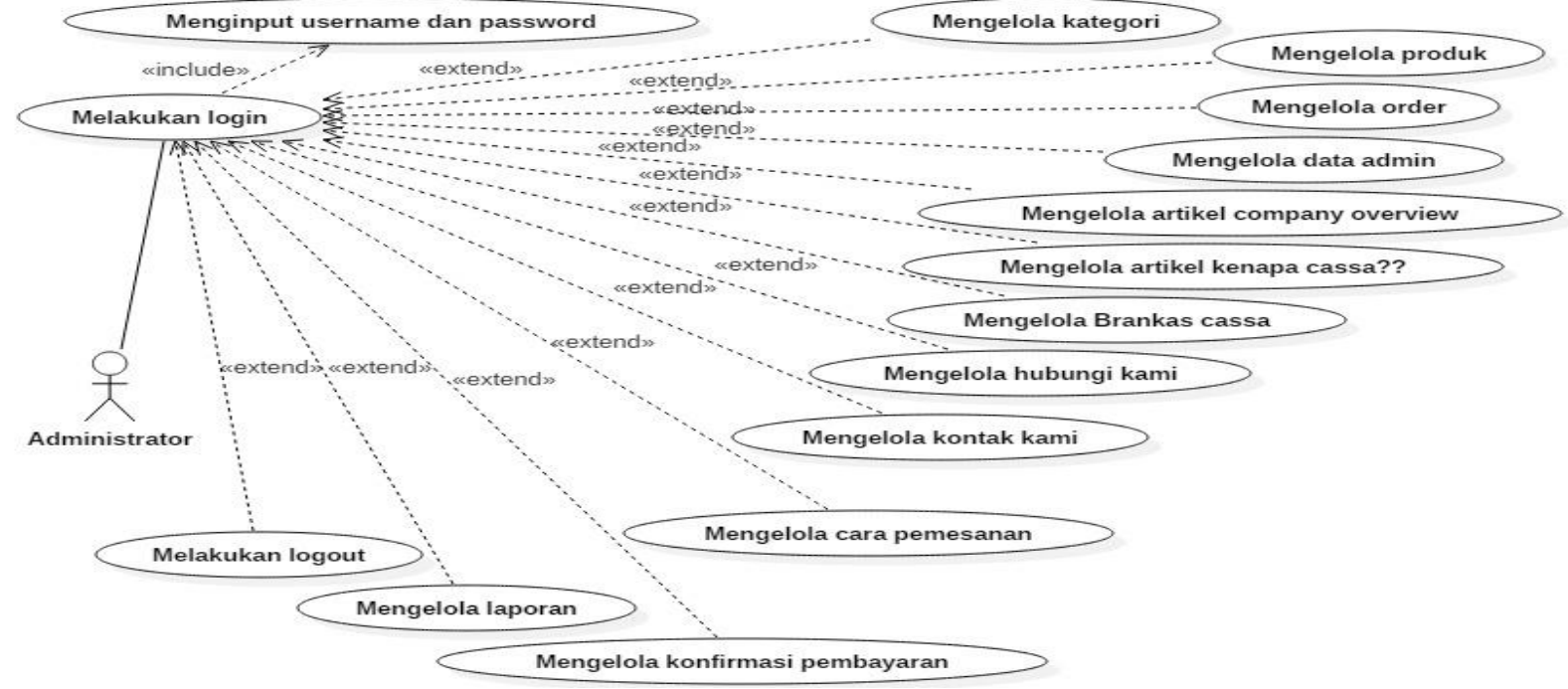

Gambar 3. Usecase Diagram Halaman Administrator

Activity diagram disini

menggambarkan detail dari proses yang

telah diterapkan pada usecase diagram.

1. Activity diagram login administrator 


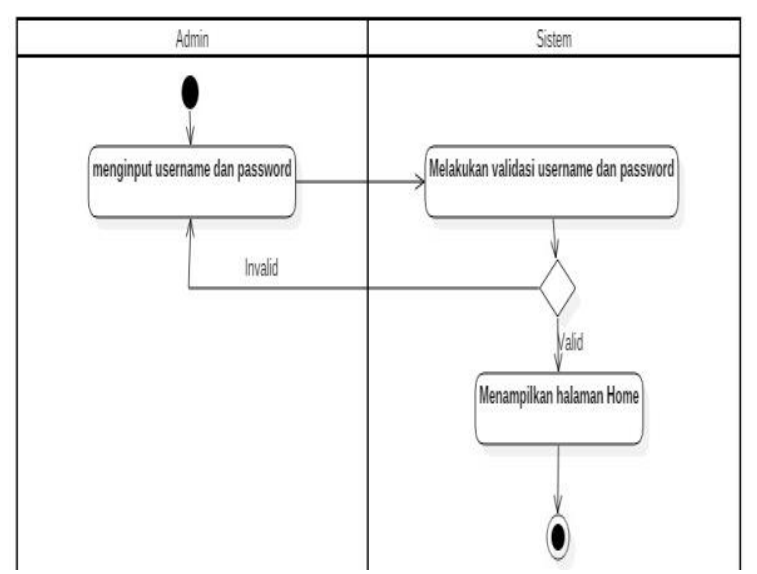

Gambar 4. Activity Diagram Login Admin

2. Activity diagram admin mengelola data kategori

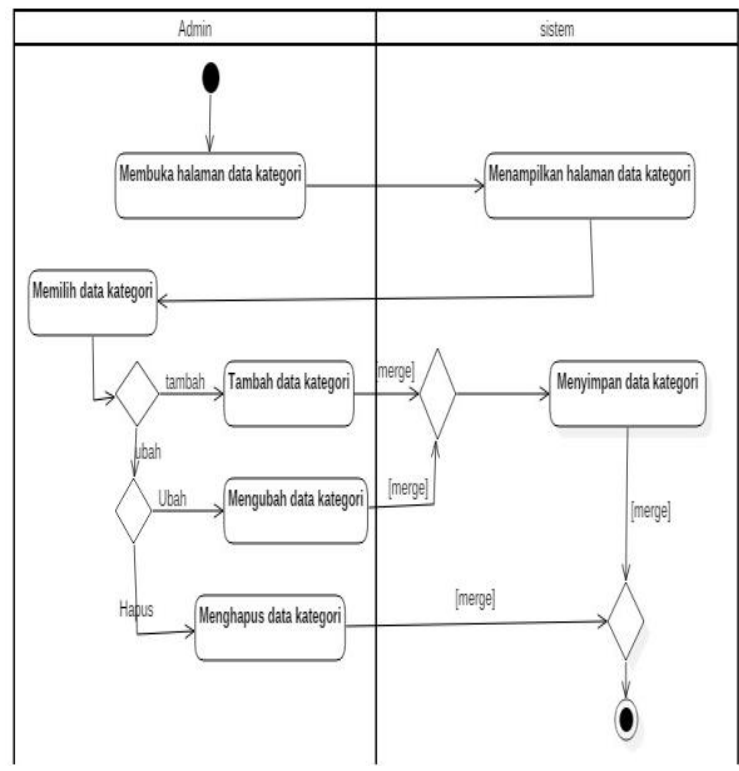

Gambar 5. Activity Diagram Mengelola Data Kategori

3. Activity diagram admin mengelola data produk

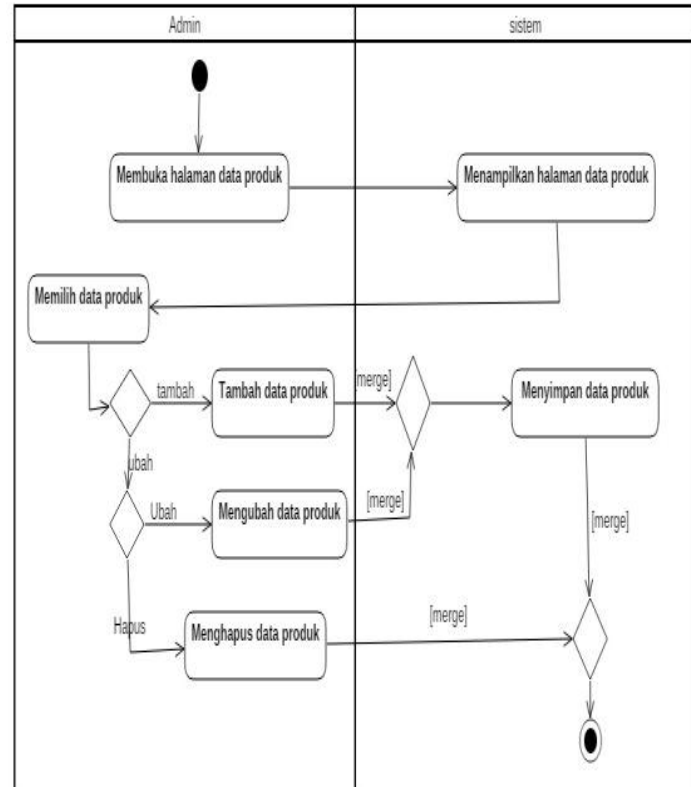

Gambar 6. Activity Diagram Mengelola Data Produk

4. Activity diagram admin mengelola data order

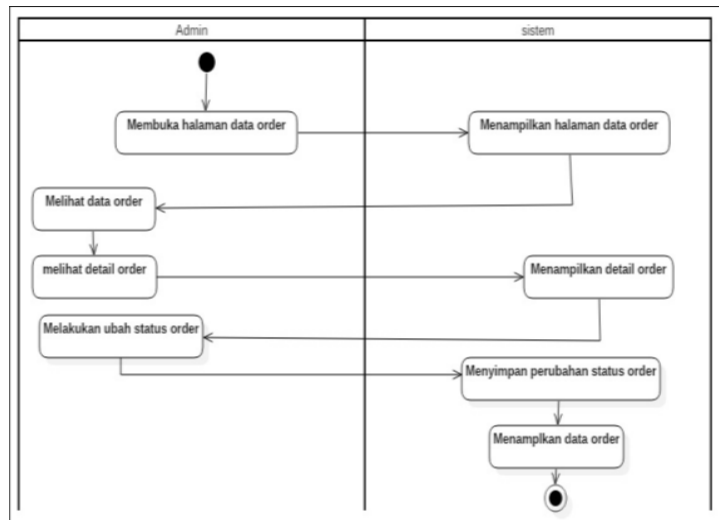

Gambar 7. Activity Diagram Mengelola Data Order

5. Activity diagram admin mengelola data admin

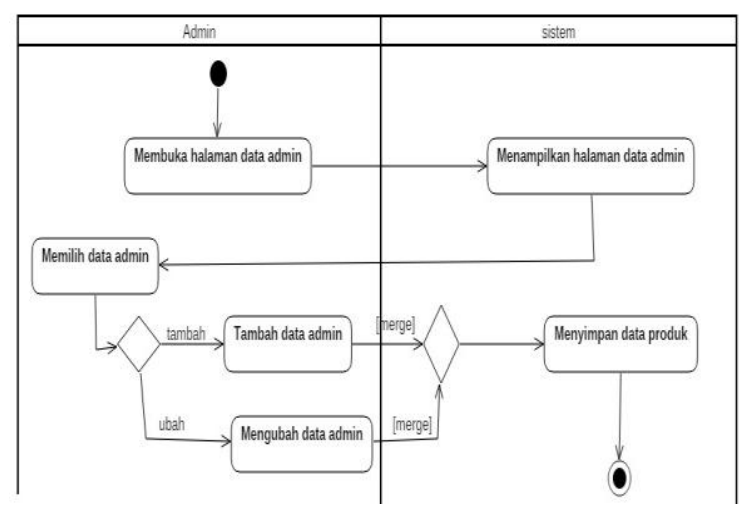

Gambar 8. Activity Diagram Mengelola Data Admin 
6. Activity diagram admin mengelola data hubungi kami

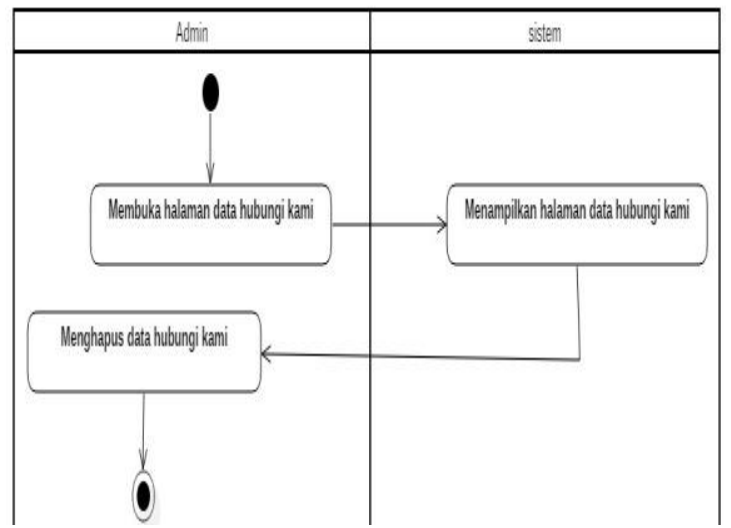

Gambar 9. Activity Diagram Mengelola Data Hubungi Kami

7. Activity diagram admin mengelola data cara pemesanan

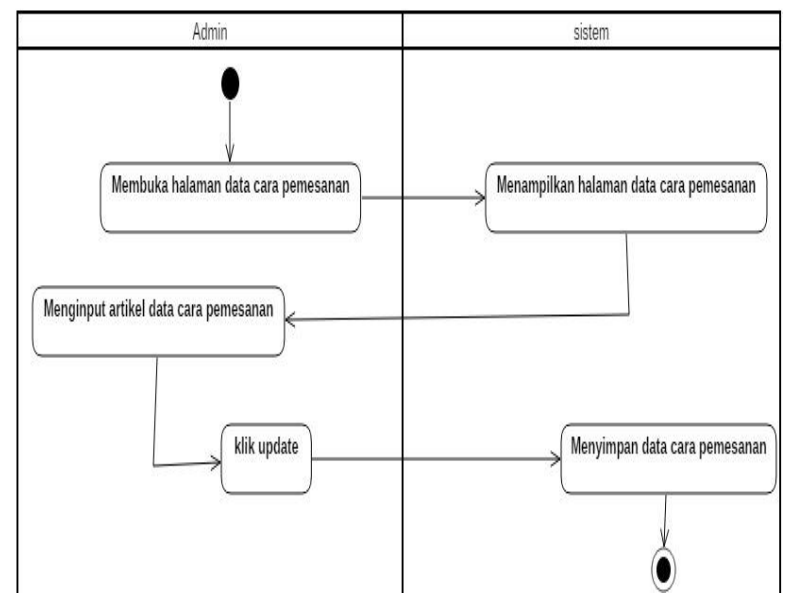

Gambar 10. Activity Diagram Mengelola Data Cara Pemesanan

8. Activity diagram admin mengelola data konfirmasi pembayaran

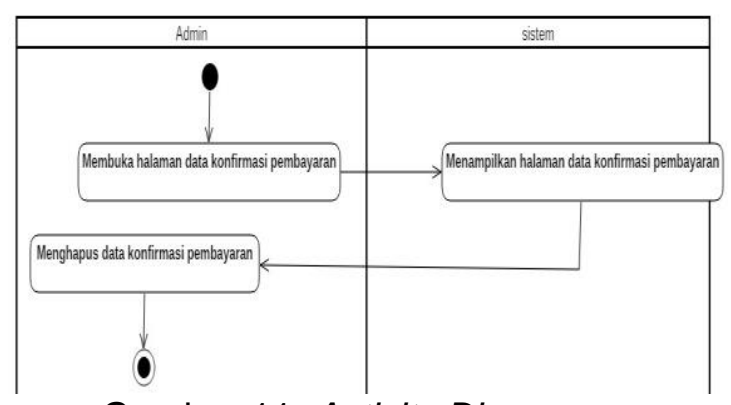

Gambar 11. Activity Diagram Mengelola Data Konfirmasi

Pembayaran

9. Activity diagram admin mengelola data laporan transaksi

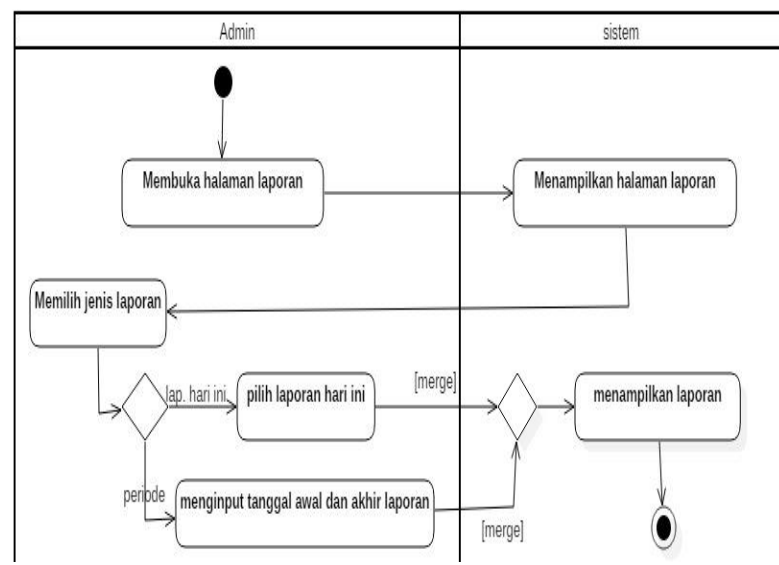

Gambar 12. Activity Diagram Mengelola Data Laporan Transaksi

Perancangan penyimpanan data untuk membangun website penjualan brankas pada PT. Persindo Pertiwi Agung menggunakan ERD (Entity Relationship Diagram) dan LRS (Logical Record Structure). Berikut pemodelan database menggunakan ERD (Entity Relationship Diagram): 


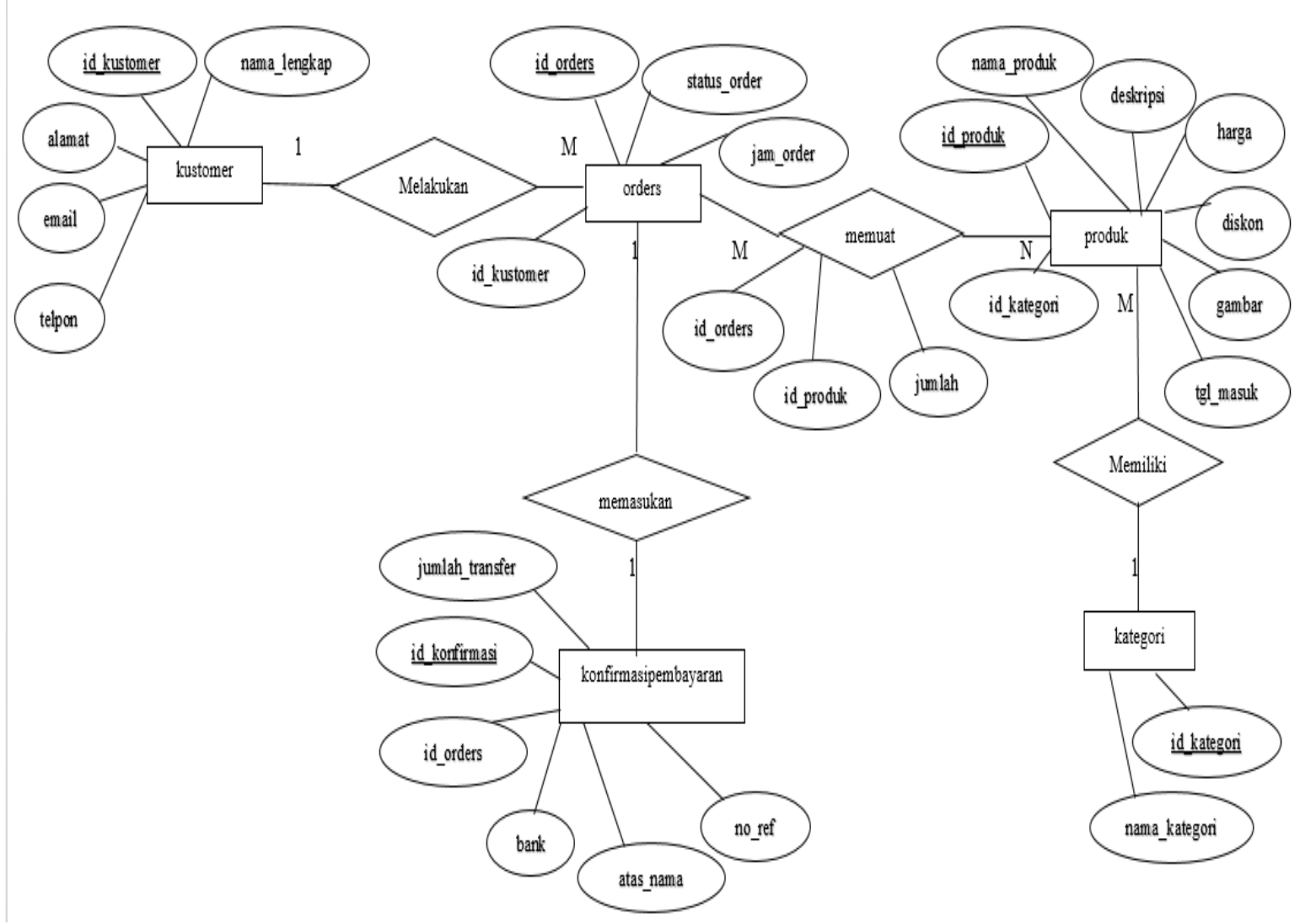

Gambar 13. Entity Relationship Diagram

Berikut pemodelan LRS (Logical Record Structure) berdasarkan pemetaan ERD (Entity Relationship Diagram):

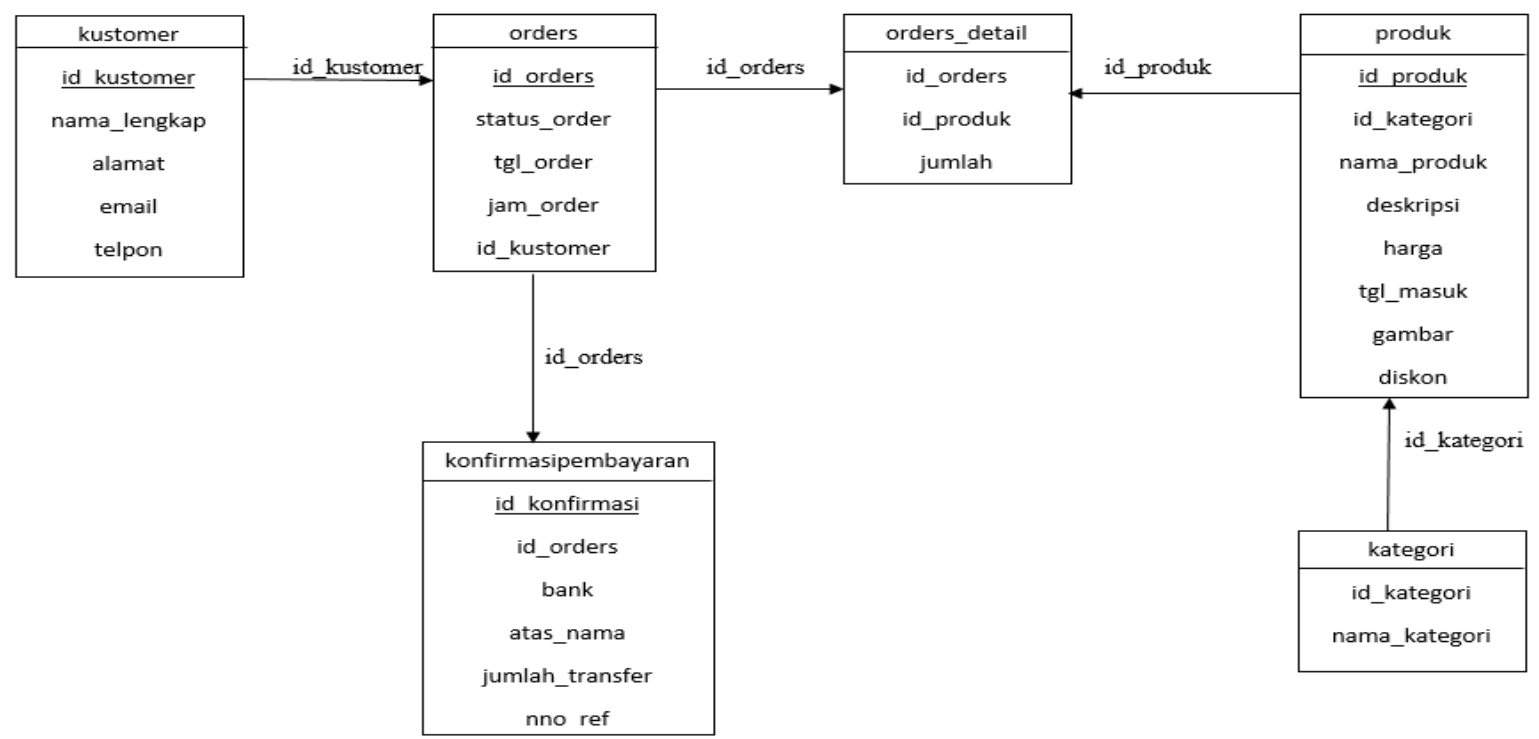

Gambar 14. Logical Record Structure

User interface beranda pada halaman pembeli, sebagai berikut : 


\section{(A) PT.PERSINDO PERTIWIAGUNG}

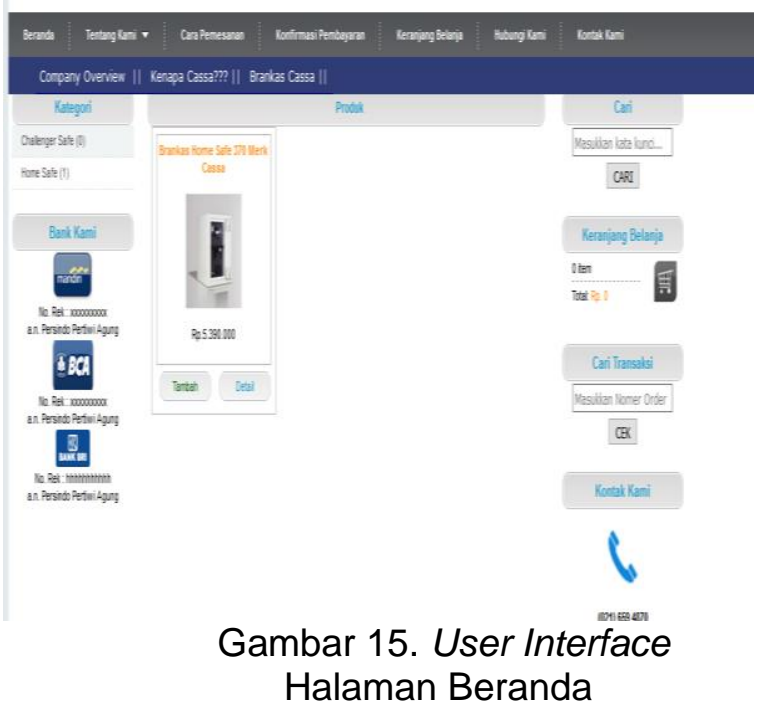

User interface login admin, sebagai berikut :

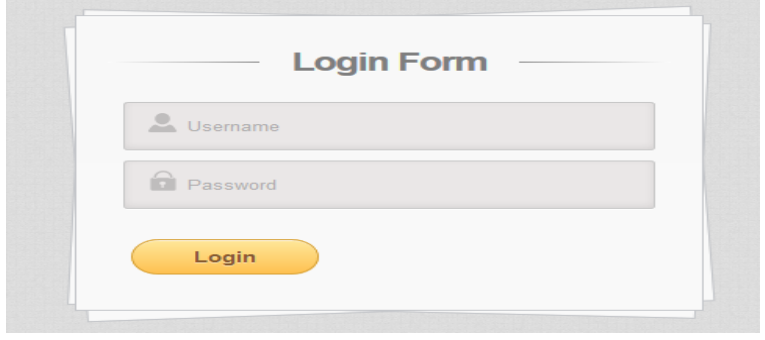

Gambar 21. User Interface Halaman Login Admin

User interface halaman home pada administrator, sebagai berikut:

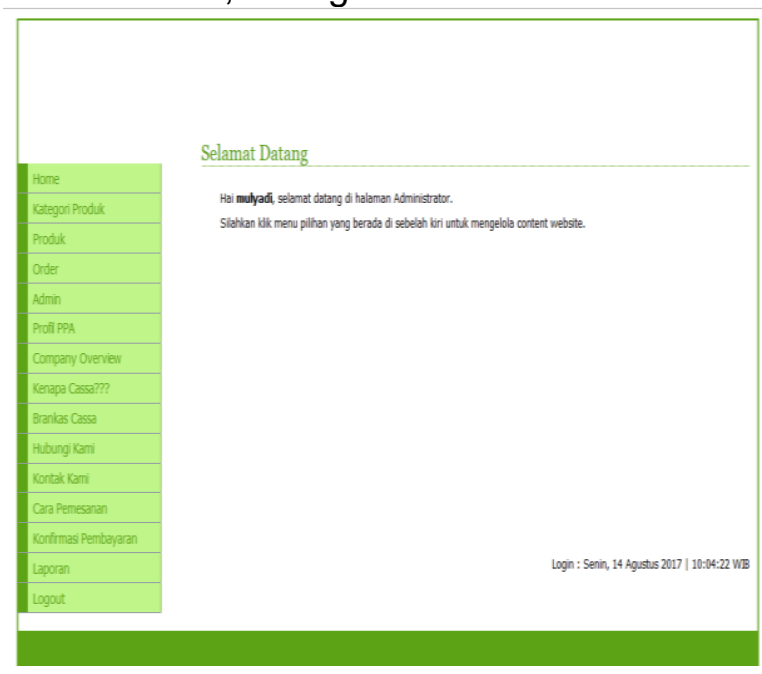

Gambar 22. User Interface Halaman Home
Dari penulisan ini, maka penulis dapat menarik kesimpulan sebagai berikut :

1. Dengan adanya website penjualan pada PT. Persindo Pertiwi Agung ini diharapkan setiap pengunjung dapat mendapatkan informasi yang cepat, tepat, dan akurat.

2. Data-data yang berkaitan dengan sistem penjualan tidak mudah hilang, tidak akan ada data yang rangkap. Hal ini dikarenakan data yang masuk sudah disimpan secara otomatis dan diintegrasikan kedalam satu database.

3. Dengan adanya sistem penjualan berbasis web ini dapat memudahkan pembeli dalam mencari informasi dan melakukan pembelian dimanapun dia berada dan staff marketing atau administrator dapat melihat data pembelian setiap saat.

4. Pada hasil laporan, laporan transaksi dapat diperoleh dengan mudah karena data bisa langsung dicetak.

Adapun beberapa saran yang dapat penulis sampaikan berkaitan dengan penelitian ini yaitu sebagai berikut :

1. Perlu adanya pengembangan yang lebih baik lagi terhadap sistemyang telah dibuat seperti pencetakan bukti pembelian pada halaman pembeli.

2. Sistem informasi status transaksi dapat diimplementasikan dengan menggunakan jasa Telekomunikasi seperti SMS Gateway.

3. Diharapkan dilakukannya upgrade terhadap kapasitas memory penyimpanan dan bandwith agar bisa mengimbangi data yang masuk.

4. Pada data admin dapat melakukan penambahan data admin.

\section{DAFTAR PUSTAKA}

Abdullah, Thamrin dan Francis Tantri. 2016. Manajemen Pemasaran. Depok: Rajawali Pers

Ardiansyah, Muhamad dan Herlawati. SISTEM INFORMASI PENJUALAN BARANG BERBASIS WEB PADA TOKO HENNY'S BUTIK BEKASI. Jurnal Sistem Informasi STMIK Antar Bangsa. Vol. IV No. 1 Februari 2015: $1-9$ 
Kadir, Abdul. 2013. Buku Pintar Programer Pemula PHP. Yogyakarta: Mediakom

Madcoms. 2016. Sukses Membangun Toko Online Dengan PHP \& MySQL. Yogyakarta: CV. Andi Offset

Mirza, Said Pahlevi. 2013. Tujuh Langkah Praktis Pembangunan Basis Data. Jakarta : PT. Elex Media Komputindo.

Mulhim, Imam. 2013. Aplikasi Informasi dengan PHP \& MySQL. Maxikom. Palembang

Riyanti, Yeni dan Taufik Baidawi. SISTEM INFORMASI PENJUALAN CAT MOBIL DAN MOTOR BERBASIS WEB PADA TOKO KARYA INDAH BEKASI. Jurnal Sistem Informasi STMIK Antar Bangsa. Vol. IV No. 1 Februari 2015: 115 - 125

Riyanto, Slamet. 2014. Kupas Tuntas Web Responsif. Jakarta. Penerbit : PT Elex Media Komputindo

Sadeli. 2013. Toko baju Online Dengan PHP dan MySQL. Palembang: Maxikom.

Sukamto, Rosa A dan Shalahuddin. 2013. Rekayasa Perangkat Lunak.Bandung: Infotmatika Bandung
Utami, Dian dan Nani Agustina. SISTEM INFORMASI PENERIMAAN SISWA BARU BERBASIS WEB PADA SMP USWATUN HASANAH JAKARTA. Jurnal Sistem Informasi STMIK Antar Bangsa. Vol. IV No. 1 Februari 2015: $126-134$

Yurianus, Lase. Pembangunan Aplikasi ECommerce Di CV. Try Berkat Faomasi. ISSN: 2089-9033 November 2016: 45-50. 